\title{
Deep Purple Urine
}

\author{
Daniel Caldeira ${ }^{1,2}$, Maria Luísa Colaço ${ }^{1}$, Susana Heitor ${ }^{1}$ and Nuno Bragança ${ }^{1}$
}

Key words: purple urine bag, purple, indigo, indirubin, urine, proteus

(Inter Med 49: 2369, 2010)

(DOI: 10.2169/internalmedicine.49.4355)

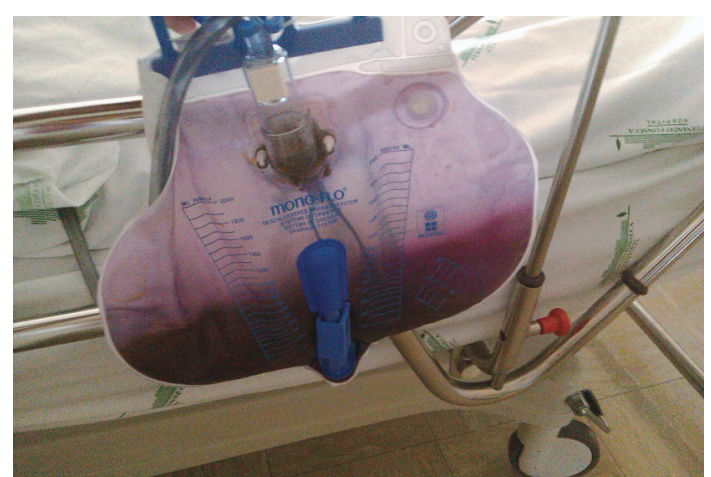

Picture 1. Purple urine bag.

A 50-year-old man was admitted with a complicated pneumonia. During his long-term inpatient stay, a plastic urinary catheter was positioned. A month after admission the patient's urine became purple (Picture 1). The patient was apyretic and did not have lower urinary tract symptoms but was constipated. Urinalysis revealed $\mathrm{pH} 7.8$, leucocyturia and negative nitrites. Urine culture isolated Proteus mirabilis (>100.000 colonies/mL), sensitive to amoxicillin/clavulanate. His urine cleared after antibiotic administration.

Purple urine bag syndrome is a rare benign entity characterized by the deposition of a blue (indigo) and red pigment (indirubin) in alkaline urine, both resulting from bacterial decomposition of indoxyl sulphate, a metabolite of dietary tryptophan (1). This condition is associated with female gender, constipation, institutionalization and use of a plastic urinary catheter (2). Proteus spp and Pseudomonas spp are the most commonly reported organisms but bacteria such as $E$. coli, Enterococcus spp., Klebsiella spp. and Morganella spp. are also associated with purple urine bag syndrome (1).

\section{References}

1. Harun NS, Nainar SK, Chong VH. Purple urine bag syndrome: a rare and interesting phenomenon. South Med J 100: 1048-1050, 2007.

2. Su FH, Chung SY, Chen MH, et al. Case analysis of purple urinebag syndrome at a long-term care service in a community hospital. Chang Gung Med J 28: 636-642, 2005.

\footnotetext{
${ }^{1}$ Serviço de Medicina III, Hospital Prof. Doutor Fernando Fonseca, Amadora, Portugal and ${ }^{2}$ Faculdade de Medicina da Universidade de Lisboa, Lisbon, Portugal

Received for publication August 11, 2010; Accepted for publication August 20, 2010

Correspondence to Dr. Daniel Caldeira,dgcaldeira@hotmail.com

(C) 2010 The Japanese Society of Internal Medicine Journal Website: http://www.naika.or.jp/imindex.html
} 